Stream: Culture/Politics/Technology, 7(1), 23-33

http://journals.sfu.ca/stream

\title{
Rising Above: Alternative Media as Activist Media
}

\section{Benjamin Anderson}

School of Communication

Simon Fraser University

\begin{abstract}
This paper asserts that truly activist media must be dually committed to critical education and to political action. Whereas my previous work has focused on the need for activist media to challenge media power from within, it is my goal here to build a model of activist media characterized by direct action through engagement in critical education and activism in both content and production. Such a model will provide insight both into the limitations of previous research on the oppositional potential of alternative media and into the challenge facing alternative media scholars and practitioners alike - that of rising above the noise of the dominant media of the cultural industry in order to communicate for radical social change.
\end{abstract}

\section{Keywords}

Alternative media, activist media, critical theory

\section{Introduction}

"[God] could alter even the past, unmake what had really happened, and make real what had never happened. As we can see, in the case of enlightened newspaper editors, God is not needed for this task; a bureaucrat is all that is required."

-Walter Benjamin, Journalism

Today's culture industry both shapes and reinforces the social totality. In contemporary media we see the limits of accepted reason, wherein the status quo imposes itself as the one and only reality, the limits of human action and the culmination of a unified, linear history of human progress (Horkheimer \& Adorno 2002). Just as the capitalist order enjoys the uncanny ability to co-opt dissidence and resistance, so too does the culture industry reappropriate creative resistance - in the commercialization of radical resources, the mass mediated smearing of radical voices, and the absorption (or dissolution) of alternative media channels through economic strangulation. As Marcuse (1964) argues, "the absorbent power of society depletes the artistic dimension [that is, the resistant creative impulse that allows for transcendence] by assimilating its antagonistic contents" (p. 61). However, such a phenomenon is not limited to a mere absorption but actual repurposing of those very antagonistic intentions - punk rock becomes soundtrack, culture jamming becomes guerrilla marketing.

This imperative of repressive legitimation - to silence and reappropriate counter-ideological voices and forms - reveals a simultaneous imperative of resistance: the need to awaken critical consciousness and renewed imagination. This need must be met, I will argue, by conflictual activist media. Such media cannot be simply conceived of as those that exist outside of commercial structures and that are characterized by critical content (although these are, indeed, important characteristics). Instead, in order to foster critical consciousness, especially today, amidst a $24 / 7$ business and entertainment cycle, such media must transcend the noise of the digital public sphere - the interference of the multitudinous voices that result in the singular voice of the status quo. Such transcendence must, as I shall demonstrate, be grounded in praxis and not simply in ideology. This means, in essence, a foundation of antagonistic action, whether through the adoption of directly al- 
ternative forms of production or through the direct affiliation with a movement or cause: not Adbusters, but Anonymous. Not editorial, but occupation. Alternative messages must cut through the noise of the contemporary media environment. As such, they must subvert the very technologies and channels which make up that environment. And they must do so actively as a pluralistic vanguard of ideological resistance.

Before delving further into this conceptualization of the role of alternative media in releasing critical consciousness ${ }^{1}$, it is important to acknowledge that not all action pertaining to the production of alternative media - political, discursive, or otherwise - is necessarily emancipatory. Perhaps it is needless to say that certain movements and their partner media are repressive (or oppressive) in nature. The conservative communicative apparatus of the Tea Party, for instance, cannot be considered to be working toward emancipated consciousness. In such an example we see an alternative form that ignores (or, better, reinforces) dominant power structures. As Patricia Mazepa (2012) succinctly argues in her exploration of regressive alternative media in Canada, "...we must consider the social relations that are manifest and invigorated in media and activism that, although appearing alternative, do not challenge power, but feed on it, cultivating it at the margins" (p. 245). To focus primarily on the negative characteristics of alternative media is also to include consideration of those media working in favor of one-dimensionality rather than against it.

Instead, in considering the action-orientation of alternative media working toward the goal of emancipated consciousness, we need only consider those that adhere to an appropriately critical vantage. Such channels would, by necessity, adhere to the kind of intolerance for unjust, violent, and otherwise oppressive reason that Marcuse (1965c) outlines in Repressive Tolerance. In Marcuse's view, "...the realization of the objective of tolerance would call for intolerance toward prevailing policies, attitudes, opinions, and the extension of tolerance to policies, attitudes, and opinions which are outlawed or suppressed" (p. 33). What this means when put into the context of action-oriented alternative media - Marcuse's irony aside - is a privileging of emancipatory, critical reason paired with the discrediting of one-dimensional opinion and the platitudes maintaining the status quo.

Just as the global order necessitates a transnational or deteritorialized disciplinary regime that reinforces this status quo through the mobilization of both force and ideology, those parties interested in its contestation must also mobilize. This mobilization must find its roots in an emancipated activist vanguard. Those class distinctions most characteristic of the struggles of the 19th and 20th centuries no longer reflect our lived reality - industrial labour has given way to what many might call socialized labour, and with this change the proletarian/bourgeois distinction is muddied (DyerWitheford, 1999). The controllers of wealth and of the ideological apparatuses grow in strength, while the disenfranchised grow in mass; whereas the industrial proletariat had the collective means to resist through labour unions and workers' organizations, the dispersed labour force of postFordism finds itself isolated, precarious, and without the safety net of the welfare state (DyerWitheford, 1999). For this reason, one might assume that it is not (at least initially) in the labouring classes that we will find the roots of emancipated existence. As Marcuse noted in 1969 "...the majority of organized labour shares the stabilizing, counterrevolutionary needs of the middle classes, as evidenced by their behaviour as consumers of the material and cultural merchandise, by their emotional revulsion against the nonconformist intelligentsia" (p. 15-16). We see similar tendencies today, though accentuated through changes in working life. As labour unions are increasingly defanged through the open-market policies of neoliberalism, the worker increasingly finds herself isolated from those means of solidarity that were at the time of Marcuse's assertion much more prevalent.

\footnotetext{
${ }^{1}$ My casual use of the word "releasing" here is meant to invoke a Gramscian understanding of ideology wherein social reality is determined through ideological struggle. In such a formulation, alternative realities can be coaxed out of the resistant imagination, their potential (I would argue) always developing.
} 
The awakening of the critical, it would seem, falls to those who can already see the fissures inherent in the global capitalist order. It is, as a result, their charge to educate and to inspire, to challenge and to shock the minds of those who are constantly and consistently fooled into opposing their own self interest in their support of the contemporary order. In this way, we might see the potential for emancipation in the critical action of activist media practitioners and organizations. This is not, necessarily, meant to invoke a kind of vanguardist orthodoxy. In fact, in a world marked by increasing precarity for knowledge workers - alternative media producers, intellectuals, etc. - such a critical milieu finds itself living within the conditions it critiques. The critical scholar, for instance, is increasingly subjected to contract and temporary work, constantly struggling for the security that once isolated this class of critical intellectuals (Dyer-Witheford, 1999). These conditions have the potential to galvanize, to build solidarity between the labouring classes, regardless of once porous class distinctions.

Elsewhere (Anderson, 2014) I have argued that in times of systemic crisis we simultaneously face a period of opportunity for emancipated thought catalysed by activist media. As crises reveal the tensions and contradictions of global capitalism, I argue, it is the charge of activist media to challenge media power and, subsequently, to reconstitute the shape and power dynamics of the media field. As Marcuse (1969) notes "The development of a radical political consciousness among the masses is conceivable only if and when the economic stability and the social cohesion of the system begin to weaken" (p. 54). This paper builds upon my previously argued view of alternative media by asserting that truly activist media must be dually committed to critical education and to political action. Whereas my previous work focused on the need for activist media to challenge media power from within the media field itself, it is my goal here to build a model of activist media characterized by direct action through engagement in critical education and activism in both content and production. Such a model will provide insight both into the limitations of previous research on the oppositional potential of alternative media and into the challenge facing alternative media scholars and practitioners alike - that of rising above the noise of the dominant media of the culture industry in order to communicate for radical social change.

However, before mapping a model of activist media, we should first consider the traditionally identified relationship between alternative media and critical education and how this interaction can be expected to contribute to emancipated consciousness in a world of alienated subjectivity. It would, perhaps, be rather naive to expect alternative media to incite any kind of mass political movement in today's society. In fact, as we will see, these media are often small both in terms of production and in reach (sometimes intentionally). It is not within their scope to bring forth revolution. Revelations, glimpses through the sheen of ideological legitimation, are perhaps the best we can expect from alternative media. Revelations through emancipatory critical content when paired with direct oppositional action should be the ultimate goal of activist media.

\section{Alternative Media and Critical Education}

Conceptual treatments of alternative media have a tendency to take on a negative character (Harcup 2011). Alternative media, the literature seems to suggest, are those media that are decidedly not something else. Alternative media are not mainstream. They may be produced by agents and organizations that are not guided by commercial interests. What is less clear, however, is how we should conceive of what alternative media are.

For the purposes of this paper, let us consider only those media that are dedicated to the promotion of a critical consciousness and the imagination of alternative potentialities. This is not to say that other forms of non-mainstream media are not alternative - surely they are. However, examples that are arranged as bureaucratic or conservative enterprises will likely contribute little toward the goal of challenging those logics and institutions they prop up through their very operation. As Horkheimer and Adorno (2002) argue, the myth of enlightened progress that permeates contempo- 
rary culture "...in the service of the present, is turning itself into an outright deception of the masses" (p. 34). This deception prioritizes the present at the expense of consideration of alternatives. Alternative media, in light of this phenomenon should ideally be those channels that challenge this legitimation through their content and form.

In order to contest the seduction of the mass media, alternative media must aim to inspire change at the level of consciousness. As Marcuse (1965) argues, "In the society at large, the mental space for denial and reflection must first be recreated" (p. 52). He continues by asserting the need for a form of political counter-education as "more than ever, the proposition holds true that progress in freedom demands progress in the consciousness of freedom" (p. 52). Such an education, being a critical endeavour, must be free of the administered totality - the instrumental rationality of the status quo and the ideological legitimation of the domination of the present over alternatives. For, as Marcuse (1969) later pointed out, under the conditions of total administration "...radical change in consciousness is the beginning, the first step in changing social existence: emergence of the new Subject" (p. 53). When freed from the imperatives of administration this emancipation of consciousness takes on the form of an education based in practice, wherein the freeing of mind and body take place as politics.

Here we see the dual-character of what I will later refer to as activist media - education and activism. In his seminal work on the history and taxonomy of zine culture, Stephen Duncombe (2008) explains that self-publication, in alternative circles, functions as a means of political expression through personal public action. In some senses self-production is direct action through the subversion of traditional productive norms. However, what we also observe in alternative media is a subversion of form in pursuit of authenticity. In opposition to a culture that reinforces the current state of affairs through its focus on the reality of today as the only reality (Marcuse 1965b), producers of alternative forms seek authenticity in expression through nonconformist, unprofessional, or otherwise non-mainstream formats and contents.

Experimentation with form, as Marcuse (1969) points out, in itself has emancipatory potential. In opposition to the professional norms of media production, alternative media have the ability to transcend Form in order to free the senses. Marcuse (1969) builds upon this assertion by arguing that "...the new art insists on its radical autonomy... Art remains alien to the [Soviet] revolutionary praxis by virtue of the artist's commitment to Form: Form as art's own reality..." (p. 39). Form, in this sense, is that character of art that transcends the current reality and pushes us to consider alternatives, shocking the spectator and imposing an alternative sensory perception.

We can observe this phenomenon in action by returning to Duncombe's (2008) treatment of the politics of authenticity that inform the production of zines. "...the refusal of some zines" he explains "to make sense or have any order can be considered a reaction against the order and sense of more recent times, in particular the tendency for expression and identity to be packaged as a nice, neat product" (p. 39). Duncombe's notable work should not be presumed to apply only to the world of zines and zine culture. In pushing past professional standards, contemporary alternative media producers, like zinesters, can confront the political through the world of their own subjective experiences. The regime of objectivity, in this sense, is not imposed upon critical alternative media, being overshadowed by a focus on the truth revealed through subjective experience.

It would seem that some attention should be paid at this point to those alternative media channels that are commonly seen, by scholars and activists alike, as the saving grace of the digital age: blogs and social media. They were heralded as the voices of revolution in the Arab Spring, and some might even go so far as to claim that the blogosphere is the new fourth estate. However, caution should be used in projecting the potential of new technologies, especially those that are highly dependent on concentrated control of the communication apparatus. These new media do, in fact, limit barriers to access - any literate person with access to a computer and the internet is able to project his or her voice into the cloud. Unfortunately, the new media are still highly controlled spaces. The barriers we observe here have less to do with expression and more to do with reception. As a 
YouTube user or blogger I can produce pretty much anything I like (with a few exceptions pertaining to pornography and hate speech). Whether or not my communication will be accessed is out of my hands. Whereas in the production of a zine (or any similar pre-digital communication) I had control over distribution, this step no longer resides with the message producer. Instead, the blogger finds himself lost in a sea of noise in which the Google algorithm is the ultimate guide. I can produce whatever I like but I have nearly no control over its access.

Unlike what one observes in more traditional alternative media, the emancipatory potential of new communication technologies will not be realized through their form but through their use. The creativity necessary for the innovative revolutionary application of communication technologies falls, as a result, upon those agents willing and able to take critically informed action. "Released from the bondage to exploitation," Marcuse (1969) explains, "the imagination sustained by the achievements of science, could turn its productive power to the radical reconstruction of experience and the universe of experience" (p. 45). Although Marcuse is alluding to the potential of science to foster global equity and to reveal the fact that alternative realities are possible, we might expand such revelations to radical new uses of technology.

A social reconstruction, such as that referenced by Marcuse, however, depends on radical application of science and technology. The potential of the Internet, for instance, is not realized through its use but its misuse. It is by actively violating norms and laws that radical media in Egypt were able to tell the story of a movement, that Anonymous (in as much as we view this group's actions as mediated communication) has been able to inspire a surge of electronic dissidence, and that figures like Julian Assange have been able to expose the gross miscarriages of justice that characterize contemporary international relations. It is for this reason that I see the potential of alternative media not wholly in their capacity to emancipate critical thought through content alone. Instead, it is in direct political practice that they are able to rise above the noise of an already saturated media field. Such practice takes the form of alternative production as well as participation in social movements. In the next section I will attempt to build a model of activist media in which media with critical content can be engaged not based on their discourse alone but through the very act of production and distribution.

\section{From Critical Media to Activist Media}

Alternative media has been conceptualized as a form of proletarian (counter-) public sphere wherein the production, content, and distribution of communicative resources takes shape outside of dominant channels (Fuchs 2010). The goal of such a public sphere, according to Fuchs (2010) is to "question dominative society" (p. 174). For Fuchs, this process depends on alternative media that are mass media (in the sense of media for and by the masses). These media should "...challenge the dominant capitalist forms of media production, media structures, content, distribution, and reception" (p. 178). Fuchs is particularly interested in examples that could be considered critical media, those that offer alternatives to the repressive messages of the mainstream media, that give voices to the voiceless and productive power to the powerless. They should be anti-hegemonic, thought provoking, multi-dimensional, and engaged in the interests of the dominated.

More, Sandoval and Fuchs (2009) argue that such critical media must also exist within a solidarity network. Isolated media, they argue, fragment the public sphere, resulting in the inability to be heard over the noise of the media field. There is, according to the authors, a danger contained within these solidarity networks that oppositional content will not disseminate outside of its boundaries. It is the critical content of these media, the argument continues, that sets them apart and that has the potential to reach audiences in new ways. "...alternative media can be understood," the authors conclude, "as media that try to contribute to emancipatory societal transformation by providing critical media content, content that questions dominative social relations" (p. 149). 
Content, however, does not push us far enough in our understanding of how alternative media can transcend the interference of an already over-saturated media field. Whereas Fuchs' consideration of alternative media pushes him to a conclusion of the emancipatory potential of content, Downing (2008) sees media technologies as having the potential to mobilize audiences, expressing doubts concerning the emancipatory potential of online activism and arguing that research on alternative media should focus more on active links to social movements. Activism, for Downing, is the key ingredient for effective social media.

Similarly, Joshua Atkinson (2008), in his analysis of the relationship between new social movements and their related media channels, demonstrated that while content was important in establishing activist network interactivity on a global level, less important in intimately organized local contexts. Instead, as he and his colleague Laura Cooley discovered later (Atkinson \& Cooley 2010), the interactivity between social movements and alternative media takes place on content and participation levels simultaneously. Thus, as 'narrative capacity'2 increases, so too do levels of closeness and interaction within the activist network.

These studies do, however, fall short in explaining how alternative media and political action actually interact. Perhaps, the answer is not to be found in the direct connection between the movement and the media but in the production thereof. Duncombe (2008) argues that the production of alternative culture's quintessential pre-digital medium - the zine - is frequently an individual labour of love, a process wherein a communicative agent attempts to subvert objectivity by projecting his or her own subjectivity into the public sphere. In this sense, the production of alternative media becomes a kind of political action. For, as Duncombe argues, in production "...the individual commits nonviolent propaganda of the deed, creating an authentic medium of communication, expressing the thoughts and feelings of an authentic individual" (p. 41).

Nicole Cohen (2012) interprets this kind of self-production through an autonomist lens, arguing that this form of cultural production finds value in meeting the needs of the alternative community rather than in surplus. As such, such an act becomes a kind of subversive politics of the present. The alternative media producer, zinester, pirate radio DJ, challenges the status quo through the very act of his or her labour. They present a radical alternative to business as usual, expressing, as Duncombe (2008) puts it, "...the one deviation rarely tolerated or represented in the mass media: rejection of the 'good life' as it is defined in consumerist terms" (29).

Activist media, by subverting the commercial process of production, frees the producer from the demands of the boardroom allowing him or her to express radical ideas designed to reveal the repression of the establishment, radical ideas that can free the senses. This does not, however, adequately confront the dominant ideology and the instrumental rationality that characterizes it.

As Marcuse (1965b) argues, reasoned discourse must be "...free from indoctrination, manipulation, [and] extraneous authority" (p. 40). In a society of concentrated administrative power, this freedom can be hard to come by. However, as highlighted above, activist media, in freeing themselves from the repressive apparatus of the mass media might be able to actualize free rational expression.

This is not to suggest that such an actualization would mimic a kind of contemporary public sphere, mirroring that of Habermas (1991). Although many would like to see potential for a new incarnation of a public sphere grounded on free access, reasoned discourse, and civic engagement (especially on the Internet), such a development is implausible. Excluding barriers to entry (which will be addressed in the following section), the primary hindrance to a mediated public sphere is the ubiquity of the mass media and their monopoly on symbolic power. According to Nicholas Garnham (1992) it is the level of autonomy enjoyed by media producers that we must consider in assessing the plausibility of such a development. It is not difficult to come to the conclusion that a

${ }^{2}$ Atkinson \& Cooley use this term to connote a social movement's ability to tell its story and to reach potential allies. 
mass mediated public sphere is simply not possible under the commercial conditions of the culture industry. More, these commercial conditions stand directly opposed to the earlier quoted call by Marcuse (1965b) that discourse be free of manipulation.

Whereas Adorno (2002a) argues that "The power of the culture industry's ideology is such that conformity has replaced consciousness" (p. 104), in a medium such as the zine or blog we see the active power of non-conformity. These forms, and by extension the bulk of alternative media, can be produced, circulated, and engaged by outsiders (Duncombe, 2008). This will not always (or even commonly) be the case, but alternative media can serve as a form of micro expression in which a producer has the complete autonomy to produce and disseminate any message he or she chooses for whichever audience he or she chooses. These messages are not tested within a public of private individuals. Instead, the expression stands out as one voice within a multitude, produced by an individual or a small group of like minded individuals. A production group is, it must be reasoned, exclusive. Not just anyone can join the team - you must fall in line ideologically.

What we see in alternative media is an exclusivity that necessarily limits the types of discourse likely to be produced. Although barriers to entry can be considerable the materials produced are intended for dissemination to an anonymous public. Alternative, and especially activist, media then seem to bridge the gap between private production and public expression. Their resources are produced behind closed doors by an exclusive group but are intended for a wider audience, likeminded or otherwise.

This differs from the production of mainstream media in that the profit motive, for alternative media, is not the primary drive. This is not to say that certain alternative media channels do not operate under a more commercial model. However, for the bulk of those media under consideration, this motive will be minimal or not existent at all. Consider, for instance, Anonymous. This hacker collective is, for all intents and purposed, a de-centralized body of volunteer practitioners informed not by the pursuit of profit but by a common interest and common goal. In fact, when viewed through the right lens, we might consider Anonymous' activities a response to Marcuse's (1965c) charge that "...the ways should not be blocked on which a subversive majority could develop, and if they are blocked by organized repression and indoctrination, their reopening may require apparently undemocratic means" (p. 45). This is, arguably, the activist purpose of Anonymous, to level the playing field and to cut through the messages of a largely repressive system of communication and governance. They expose, hack, and otherwise undermine those forces that they see as contributing to a system of indoctrination. We can argue about Anonymous' methods, of course, but, at the end of the day, they have found a platform through their very subversion of the accepted media of expression. Through this misuse of the communicative apparatus they are able to rise above the interference of the culture industry whilst simultaneously challenging its monopoly on symbolic power.

What we see here, then, are activist media marked by an oppositional mode of production in which traditional productive practices that find themselves increasingly informed by commercial logics are foregone in favour of small-scale, alternative forms meant as much as statements of resistance as they are for the actual process of production. These media are marked by critical content, as explored in the first section, but they also put that content into practice through their direct and deliberate subversion of media norms and practices. They find a platform for their content through the use and misuse of media technologies and aim to reveal the manipulative qualities of mass media by using production as a political action.

A longer treatment of such media would, almost necessarily, need to focus on specific case studies. I have briefly touched on Anonymous as an example of subversive production but a closer look at those media that find themselves tied more directly to social movements - IndyMedia for example - would be warranted in a more substantial treatment of this subsection of alternative media. This said, the preceding discussion is a first step in a conceptual understanding of such a model of communication. One that is, admittedly, limited by both its scope and its subject. 


\section{Limits of Activist Media}

As mentioned early in this paper, production and reception of alternative media can often be seen as a labour of love. Alternative media organizations, especially those that might be considered activist or oppositional, are largely under-funded, staffed by volunteers, and supported through a very limited network of engaged allies. As such, there are certain barriers to these media's ability to actualize their activist goals.

First, as Cohen (2012) notes, volunteer labour is often taken up by those who enjoy a certain amount of social and financial privilege. Globally, she explains, alternative media is produced mostly in North America and Western Europe; domestically, by former mass media practitioners, unpaid interns, and others who can 'afford' to volunteer their labour power. In a society in which fun is an administered cultural imposition - "Organized freedom," Says Adorno (2002b) "is compulsory" (p. $190)$ - there are a limited few who have the necessary critical consciousness to participate, fewer with the financial freedom. Our free time - that time meant for recuperation of labour power - is organized, controlled. This control, for Adorno (2002b) is meant to stifle imagination. There is, almost inevitably, a lack of labour within the alternative media and it is not due to organizational financial challenges.

This reality of existence under capitalism, wherein we depend on the system for the meeting of our physical needs, limits participation in alternative media to the privileged. As a result, it is from that privileged sector that content is produced. As a result, activist forms of media are limited to a focus on those issues and movements seen as important to a minority that finds itself free of the material realities that plague a majority of the population. Can we trust such a privileged minority to speak on behalf of the majority?

Marcuse (1969) notes the limited potential of the proletariat to recognize its own subjugation due to the ubiquity and power of the mass media. "The power of corporate capitalism" he explains "has stifled the emergence of such a consciousness and imagination; its mass media have adjusted the rational and emotional faculties to its market and its policies and steered them to defence of its dominion" (p. 15). Keeping this in mind, perhaps it is better to consider whether a pre-emancipated proletariat can act on its own behalf. The emancipated consciousness allows the subject to explore the potentialities of form and content - but it appears that such consciousness must come first in the individual or the minority. In fact, this must, it seems, be a gradual process, as Marcuse (1969) strongly opposes social reorganization (following the Bolsheviks) that depends on coercion over enlightenment. Ultimately, he argues that "...the revolution must be at the same time a revolution in perception which will accompany the material and intellectual reconstruction of society..." (p. 37). It would seem that such a revolution in perception would depend upon critical education of the majority by those who enjoy a certain level of social privilege; for, as Badiou (2012) argues, philosophy is the work of those with the privilege to engage it. Leading the vanguard must be the emancipated few who pave the way for others, who fight for the reorganization of society and work to educate others. Again, this idea of a privileged vanguard is problematic as it relates to subjectivity and to the class divisions of the digital age. As I previously noted, these class divisions appear to be less concrete than in earlier periods. The radical vanguard of Marcuse's day is now increasingly precarious. The intellectual and the activist no longer emerge from outside the material conditions of the labouring classes, but actually share them. The activist media, for this reason, are ideal laboratory experiments for the process of emancipating consciousness in the collective subject. For in activist media we observe both education and action, emancipation and resistance.

\section{Conclusion}

The power of the culture industry is the imposition of sameness, of conformity; to resist is to become an outsider (Horkheimer \& Adorno 2002). Culture, in this sense becomes an expression of 
democracy, albeit a manipulated one. The culture industry will always reproduce the current state, imposing a circular regime of sameness. However, in activist alternative media we glimpse the benefits of existence as an outsider. As Duncombe (2008) puts it, "The winners are celebrated with power, wealth and media representation. The losers, the majority of Americans [and, indeed, people as a whole], are invisible" (pg. 25). Autonomous expression is a means for visibility. In producing a zine, writing a blog, or hosting a podcast, the invisible loser can be heard, can challenge the totality of conformity. Herein lies both the potential and the challenge of alternative media.

For in a world where everyone can have a voice, no one can be heard. Everyone has a blog, a twitter account, a comment to post on a news article. Whereas when Horkheimer and Adorno wrote Dialectic of Enlightenment the culture industry had a monopoly on public expression, it now has a monopoly on public reception. The conformity of reception that characterized the age of mass media has given way to a multiplicity in production that gives everyone the tools and opportunity to produce their own content. ${ }^{3}$ We can't hear the song for the choir. The world is incredibly noisy, and it is the challenge of alternative media (contributors to that noise) to find a way of rising above.

To be heard in a noisy restaurant one should not (but often does) shout louder. This leads to a rising cacophony, the end product being a ruined dinner. Instead, one should lean in, whisper, pay particular attention to the listener's ability to hear, to understand. Similarly, in a noisy media environment, the activist media should not simply contribute to the cacophony. They should explore the means at their disposal to circumnavigate it, to communicate through alternative channels in active, engaged ways.

Emancipated consciousness will not be realized by simply creating more content. Attention must be stolen from the centres of mediated power. Truly activist media producers must, it seems, become experts of disruption and subversion in order to be heard. This might take the form of the violation of normative standards of use of technology, as we see with Anonymous. It might also be realized through active engagement within a solidarity network - as in the use of media within an activist network for their own internal purposes regardless of external impact. Regardless, we should note at this point that critical expression, no matter its reception (or lack thereof), is a worthy endeavour. In fact, it is in the generation of content that an activist-producer is able to exercise his or her own subjective autonomy. This is an important first step in the process of emancipation and one that should not be discounted. Such an exercise is both emancipatory and resistant as it is also a symbolic rejection of the accepted ways of producing. In producing activist media, no matter its reception, the activist-producer rejects the status quo and affirms the alternative - that of creative self-organization and administration. As Cohen (2012) notes in echoing Virno and Hardt, "The notion of self-determined work is reflected in ... self-valorisation" (p. 211). This localized, independent way of being reveals a productive process geared toward self-fulfilment and emancipation rather than one that exists solely for the pursuit of profit or for the meeting of rhetorical ends.

The preceding paragraphs serve only as the first step toward a conceptual foundation of emancipatory activist media. They are meant to establish a basis for critical discussion concerning the emancipatory and oppositional roles and potentials of activist media, pushing the beyond a simple faith of democratic potential mediated pseudo-public sphere ${ }^{4}$. By focusing on the dual-character of these media - their focus on critical content as well as subversive action - it was my goal to highlight the ways in which alternative production as action can elevate activist discourse above the

\footnotetext{
${ }^{3}$ This is, admittedly, an overstatement in a globalized world. The electronic media devices that individuals in the west take so for granted are highly dependent on the outsourcing and distribution of Fordist regimes of production that effectively relocate poverty, slave labour, and poor working conditions to the global south. For more on this, see Vincent Mosco's (2014) primer To the Cloud: Big Data in a Turbulent World.

${ }^{4}$ I'm thinking here of the popular tendency to view events like Occupy and the Arab Spring as evidence of digital media as inherently emancipatory, as a panacea. A good example of this tendency can be found in Angie Herrera's (2014) Revolution in the Age of Social Media: The Egyptian Popular Insurrection and the Internet.
} 
noise of the contemporary media environment and, as a result, inspire both subjective reflection and active resistance. This is not to bow to the the instrumentally rational standard of effective message reception. Indeed, as noted, the communications of activist media are meant to subvert the current norms of the mainstream media. As such, they should, by their very nature, shock audiences into a state of critical reflection. Although the scope of the current paper limits my ability to consider fully this dynamic, future work should (and will) attempt to engage reception of these media who engages them and to what end. As Christian Fuchs (2010) posits, critical alternative media offer alternatives to dominant repressive perspectives. As such, we should consider not only the critical production of communication but also its critical reception.

More, subsequent research should engage the question of the relationship between activist production of media and engaged political action within those media's solidarity networks. This work has been started by the likes of Atkinson (2008) and Atkinson and Cooley (2010), but falls short of drawing a compelling theoretical thread between these two distinct but interrelated spheres of action. More, studies concerning this interaction tend to focus on message reach and impact rather than the holistic consideration of activist production and resistance performance. It is important that we continue to explore this relationship, as to simply accept alternative media as those forms that take place outside of the mainstream without considering their potentials for resistance is to neglect their emancipatory character - both in production and in reception.

\section{References}

Adorno, T. (2002). The culture industry reconsidered, In T. Adorno \& J. Bernstein (ed.), The culture industry: Selected essays on mass culture (pp. 98-106). London: Routledge.

Adorno, T. (2002). Free time. In T. Adorno \& J. Bernstein (ed.), The culture industry: Selected essays on mass culture. London: Routledge, 98-106.

Anderson, B. (2014, September). Opportunity in crisis: Alternative media and capitalist legitimation. Paper presented at Crisis \& Social Change: Toward Alternative Horizons, University of Cambridge.

Atkinson, J. (2008). Towards a model of interactivity in alternative media: A multilevel analysis of audiences and producers in a new social movement network. Mass Communication and Society, 11(3), 227-247.

Atkinson, J., \& Cooley, L. (2010, July). Narrative capacity, resistance performance and the 'shape' of new social movement networks.' Paper presented at the annual meeting of the NCA 95 ${ }^{\text {th }}$ Annual Convention. Chicago, IL. Retrieved from http://citation.allacademic.com/meta/p364932_index.html

Badiou, A. (2012). Philosophy for militants (B. Bosteels, Trans.). London: Verso.

Benjamin, W. (2008). Journalism. In M. Jennings, B. Doherty and T. Levin (Eds.) The work of art in the age of its technological reproducibility, and other writings on media. Cambridge, MA: Belknap Press, 353-354.

Cohen, N. S. (2012). From alienation to autonomy: The labour of alternative media. In K. Kozolanka, P. Mazepa, and D. Skinner (Eds.) Alternative media in Canada. Vancouver: UBC Press, 207-225.

Downing, J. (2008). Social movement theories and alternative media: An evaluation and critique. Communication, Culture \& Critique, 1 (1), 40-50.

Duncombe, S. (2008). Notes from underground: Zines and the politics of alternative culture. Bloomington: Microcosm.

Dyer-Witheford, N. (1999). Cyber-Marx: Cycles and circuits of struggle in high-technology capitalism. Urbana: University of Illinois Press.

Fuchs, C. (2010). Alternative media as critical media. European Journal of Social Theory, 13 (2), 173192. 
Garnham, N. (1992). The media and the public sphere. In C. Calhoun (Ed.) Habermas and the public sphere. Cambridge, MA: MIT Press, 359-376.

Harcup, T. (2011). Alternative journalism as active citizenship. Journalism, 12 (1), 15-31.

Herrera, A. (2014). Revolution in the age of social media: The Egyptian popular insurrection and the internet. London: Verso.

Horkheimer, M. and Adorno, T. (2002). Dialectic of enlightenment: Philosophical fragments (G. Schmid Noerr, Ed., E. Jephcott, Trans.). Stanford: Stanford University Press.

Marcuse, H. (1964). One-dimensional man. Boston: Beacon.

Marcuse, H. (1965a). The individual in the great society. In A. Feenberg and W. Leiss (Eds.) The essential Marcuse: Selected writings of philosopher and social critic Herbert Marcuse. Boston: Beacon, 3-12.

Marcuse, H. (1965b). Remarks on a redefinition of culture. In A. Feenberg and W. Leiss (Eds.). The essential Marcuse: Selected writing of philosopher and social critic Herbert Marcuse. Boston: Beacon, 13-31.

Marcuse, H. (1965c). Repressive tolerance. In A. Feenberg and W. Leiss (Eds.) The essential Marcuse: Selected writings of philosopher and social critic Herbert Marcuse. Boston: Beacon, 32-59.

Marcuse, H. (1969). An essay on liberation. Boston: Beacon Press.

Mezepa, P. (2012). Regressive social relations, activism, and media. In K. Kozolanka, P. Mazepa, and D. Skinner (Eds.) Alternative media in Canada. Vancouver: UBC Press, 244-263.

Mosco, V. (2014). To the cloud: Big data in a turbulent world. Boulder: Paradigm Publishers.

Sandoval, M. and Fuchs, C. (2009). Towards a critical theory of alternative media. Telematics and Informatics, 27, 141-150. 